
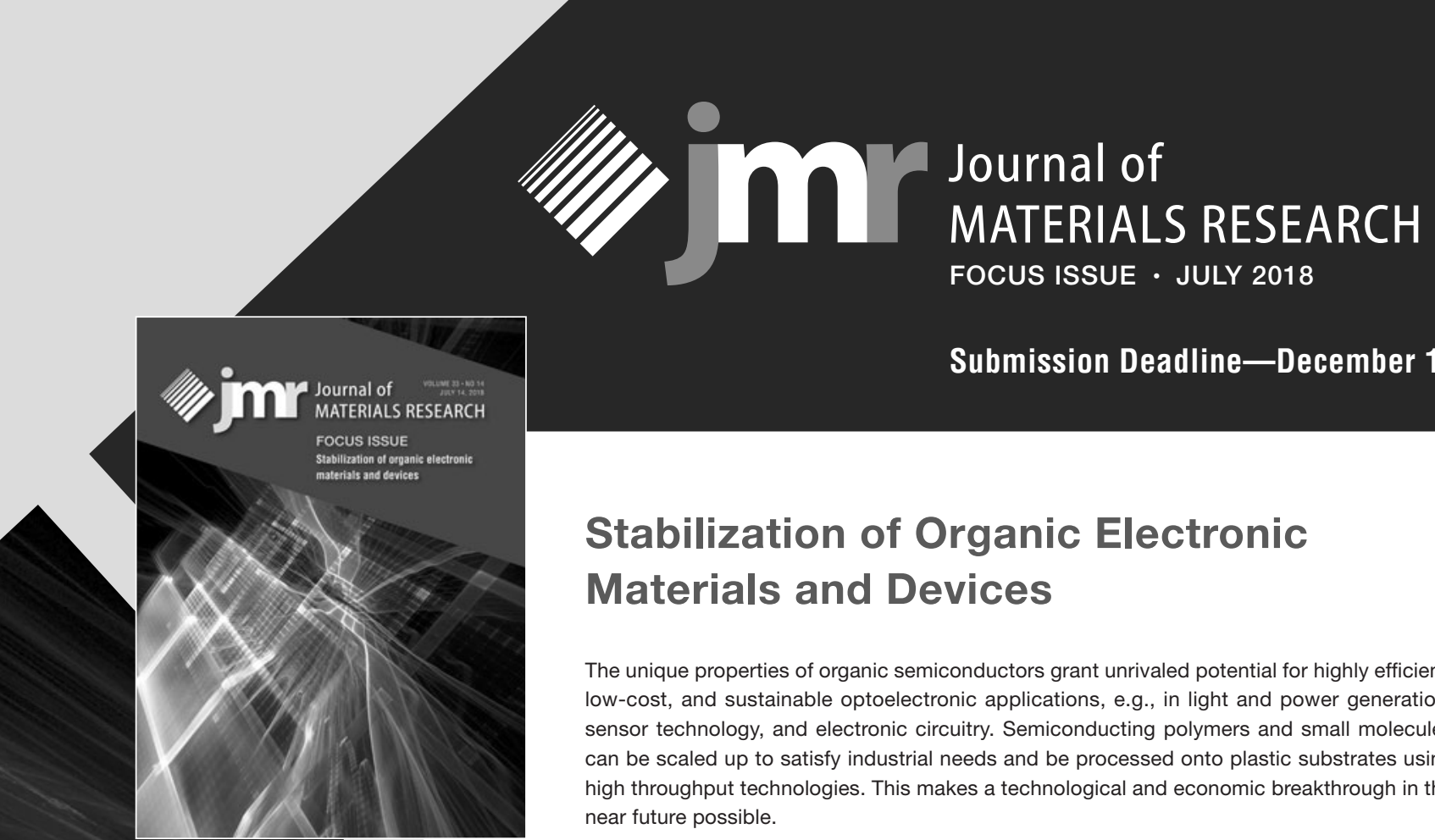

Submission Deadline—December 1, 2017

\title{
Stabilization of Organic Electronic Materials and Devices
}

The unique properties of organic semiconductors grant unrivaled potential for highly efficient, low-cost, and sustainable optoelectronic applications, e.g., in light and power generation, sensor technology, and electronic circuitry. Semiconducting polymers and small molecules can be scaled up to satisfy industrial needs and be processed onto plastic substrates using high throughput technologies. This makes a technological and economic breakthrough in the near future possible.

Despite the widespread potential, organic electronics face important challenges. A critical factor in the overall cost assessment is the lifetime of a final product. The current generation of organic electronics offers limited stability and need to be encapsulated using costly barrier materials. A fundamental understanding of the processes governing performance decay paired with innovative material approaches is essential for enhancing the longevity of organic optoelectronic devices and thus guaranteeing market readiness. This Focus Issue will address both mechanistic aspects that determine the lifetime of materials and devices as well as future strategies with practical relevance for increasing the lifespan and reliability of organic electronics.

Contributed articles are sought in the following areas:

- Fundamental degradation mechanisms in active materials and finished devices (photophysical and spectroscopic studies)

- Novel material concepts leading to enhanced intrinsic material stability (materials design, predictive simulations, materials synthesis, etc.)

- Extrinsic material concepts for stabilizing organic electronics materials (stabilizing additives, optimal microstructure, crystallinity, etc.)

- Realization of stabilization approaches in device structures with practical relevance

\section{GUEST EDITORS}

Christoph Brabec, Friedrich-Alexander University Erlangen-Nuremberg, Germany Hans-Joachim Egelhaaf, Bavarian Center for Applied Energy Research (ZAE Bayern), Germany Michael Salvador, King Abdullah University of Science and Technology, Saudi Arabia

\section{MANUSCRIPT SUBMISSION}

To be considered for this issue, new and previously unpublished results significant to the development of this field should be presented. The manuscripts must be submitted via the JMR electronic submission system by December 1, 2017. Manuscripts submitted after this deadline will not be considered for the issue due to time constraints on the review process. Please select "Focus issue: Stabilization of organic electronic materials and devices" as the manuscript type. Note our manuscript submission minimum length of 5500 words, with a maximum of 8 figures. Review articles must be pre-approved by proposal to the Editorin-Chief. The proposal form and author instructions may be found at www.mrs.org/ jmr-instructions. All manuscripts will be reviewed in a normal but expedited fashion. Papers submitted by the deadline and subsequently accepted will be published in the Focus Issue. Other manuscripts that are acceptable but cannot be included in the issue will be scheduled for publication in a subsequent issue of $J M R$.

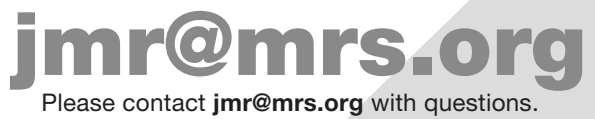





\title{
MATERIALS RESEARCH SOCIETY ${ }^{\circledR}$
}

\section{Board of Directors Officers}

Susan Trolier-McKinstry, President

Kristi S. Anseth, Past President

Sean J. Hearne, Vice President

Eric A. Stach, Secretary

David J. Parrillo, Treasurer

Todd M. Osman, Executive Director

\section{Directors}

Charles T. Black

Li-Chyong Chen

Matt Copel

Paul Drzaic

Dawnielle Farrar-Gaines

Yury Gogotsi

Claudia Gutierrez-Wing

Young-Chang Joo
Karen L. Kavanagh

Lincoln Lauhon

Christine Ortiz

Sabrina Sartori

Magaly Spector

Molly M. Stevens

Anke Weidenkaff

\section{Publications Committee}

\author{
S.P. Baker, Chair
}

T.J. Balk, Editors Subcommittee

A.J. Hurd, New Publication Products Subcommittee

R.J. Nemanich, Publications Quality Subcommittee

\section{MRS Committee Chairs}

B.M. Clemens, Academic Affairs

A. Polman, Awards
K. Whittlesey, Government Affairs
T. Aselage, Meetings
S.M. Haile, Member Engagement

E. Kupp, Public Outreach

S.P. Baker, Publications

\section{MRS Headquarters}

T.M. Osman, Executive Director

J.A. Dillen, Director of Finance and Administration

D. Dozier, Director of Government Affairs

P.A. Hastings, Director of Meeting Activities

E.M. Kiley, Director of Communications

Journal of Materials Research Founding Sponsors

Allied-Signal Inc.

Xerox Corporation

\begin{abstract}
About the Materials Research Society
The Materials Research Society (MRS ${ }^{\circledR}$ ) is a not-for-profit scientific association founded in 1973 to promote interdisciplinary goal-oriented basic research on materials of technological importance. Membership in the Society includes over 16,000 scientists from industrial, government, and university research laboratories in the United States and abroad.

The Society's interdisciplinary approach to the exchange of technical information is qualitatively different from that provided by single-discipline professional societies because it promotes technical exchange across the various fields of science affecting materials development. MRS sponsors two major international annual meetings encompassing many topical symposia, as well as numerous single-topic scientific meetings each year. It recognizes professional and technical excellence, conducts tutorials, and fosters technical exchange in various local geographical regions through Section activities and Student Chapters on university campuses.
\end{abstract}

Disclaimer: Authors of each article appearing in this Journal are solely responsible for all contents in their article(s) including accuracy of the facts, statements, and citing resources. Facts and opinions are solely the personal statements of the respective authors and do not necessarily represent the views of the editors, the Materials Research Society, or Cambridge University Press.
MRS journals maintain a proud tradition of editorial excellence in scientific literature. The Journal of Materials Research, the archival journal spanning fundamental developments in materials science, is published twenty-four times a year by MRS and Cambridge University Press. MRS Bulletin is a premier source for comprehensive research trends and a timely scan of professional activities. MRS Communications is a full-color letters and prospectives journal focused on groundbreaking work across the spectrum of materials research. MRS Energy \& Sustainability-A Review Journal publishes reviews on key topics in materials research and development as they relate to energy and sustainability. MRS Advances is a peer-reviewed online-only journal featuring impactful and emerging research, designed to reflect the way materials researchers work, write, publish and share their results.

The Journal of Materials Research is free electronically to all MRS regular and student members. See inside front cover for subscription rates for Journal of Materials Research.

MRS is an Affiliated Society of the American Institute of Physics and participates in the international arena of materials research through associations with professional organizations.

For further information on the Society's activities, contact MRS Headquarters, 506 Keystone Drive, Warrendale, PA 15086-7573; telephone (724) 779-3003; fax (724) 779-8313. 

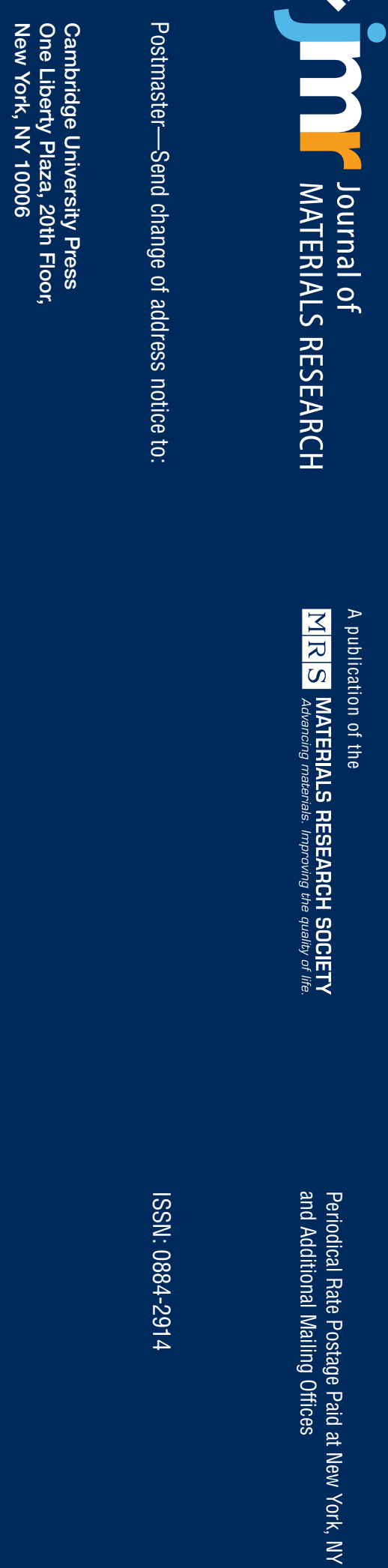